\title{
Applying Computer-based Testing in Palestine: Assessing Fourth and Fifth Graders Inductive Reasoning
}

\author{
Mojahed Mousa \\ $\mathrm{PhD}$ candidate, Doctoral School of Education at the University of Szeged \\ H-6722 Szeged, Petőfi sgt. 30-34., Hungary \\ E-mail:mojmousa@gmail.com \\ Gyöngyvér Molnár \\ Professor of Education, Institute of Educationat the University of Szeged \\ H-6722 Szeged, Petőfi sgt. 30-34, Hungary \\ E-mail: gymolnar@edpsy.u-szeged.hu
}

$\begin{array}{lcc}\text { Received: May 5, } 2019 & \text { Accepted: June 11, } 2019 \quad \text { Published: August 1, } 2019 \\ \text { doi:10.5296/jse.v9i3.14799 } & \text { URL: https://doi.org/10.5296/jse.v9i3.14799 }\end{array}$

\begin{abstract}
Computer-based assessment offers unique possibilities for collecting data about student's cognitive development and using this data to improve learning. Its innovative approach to assessment (Thurlow, et al., 2010) encourages educational systems worldwide to involve it. This study introduces and tests the applicability of computer-based testing in the Palestinian schools by measuring fourth $(\mathrm{N}=123)$ and fifth $(\mathrm{N}=125)$ graders (age $\pm 9-10)$ inductive reasoning skills. The online test consists of 60 items measuring figural series (18 items), figural analogy (18 items), numerical series (16 items) and numerical analogy (8 items). Automatic scoring was used and at the end of the test instant feedback was provided for the students. The online data collection was carried out via the eDia platform (Molnár \& Csapó, 2019) using the schools' infrastructure. The time spent to complete the test was approximately 60 minutes. The reliability (Cronbach-alpha) of the inductive reasoning test was .807 . The test proved to be difficult for the students $\mathrm{M}=25.29 \% \mathrm{SD}=10.94 \%$. There were no significant gender differences (M_girls=26.75, M_boys $=24.13 ; \mathrm{t}=-1,92, \mathrm{p}>.05$ ). Students with higher school achievement proved to be more developed in inductive reasoning skill ( $\mathrm{M}$ sschool_advanced $=40.08$, M_school_average $=25.48 ;$ M_school_low $=14.50, \mathrm{~F}=528.16, \mathrm{p}<.001 ; \mathrm{r}=.89, \mathrm{p}<.001$ ), which indicates that its assessment and development must be included in the Palestine school
\end{abstract}




\section{Macrothink}

Journal of Studies in Education

ISSN 2162-6952 2019, Vol. 9, No. 3

curriculum. This study provided evidence that (1) computer-based testing can be introduced in the Palestinian school system even at early ages; (2) the development of inductive reasoning is an integral part of the Palestinian school curriculum, thus the stimulation of it is pursued explicitly in Palestinian schools.

Keywords: computer-based assessment, inductive reasoning, Palestinian school system 


\section{Introduction}

Technological tools become a vital part of our daily lifestyle. Children are the most affected and attracted part of the society by it. It not just affects the way they live and play but also the way they learn and gain knowledge since technology covers the education field in form of e-learning and edutainment. Implementing technology in education has many advantages over traditional methods. It is considered as a modern and attractive way regarding the given value as it is in computer games which cannot be found in the traditional tools (Bottino et al., 2007). Such features make scholars to suggest developing computerised testing to have new and modern way of educational evaluation (Csapó, Lörincz \& Molnár, 2012) and improve the assessment (Csapó, Ainley, Bennett, Latour \& Law, 2012).

In this study, we explore the possibility of using computerized tests by pupils in an early school age. An online test was used to collect data by measuring fourth and fifth grade students' inductive reasoning (IR) skill. Students were tested in their own schools using the school facilities.

\section{Computer-based assessment of inductive reasoning in Palestinian educational context}

\subsection{Computer-based assessment}

Computer-based assessment (CBA) becomes more broadly demanded by educational systems around the world. Several studies have been conducted to evaluate the comparability of CBA and paper-and-pencil scores (Csapó, Molnár \& Nagy, 2014; Clariana \& Wallance, 2002; Csapó, Molnár \& Tóth, 2009), to measure the effect of administration mode and to discuss the possibilities and challenges CBA offers over traditionally assessment methods. These possibilities and advantages cover two main perspectives: practically (by giving immediate feedback, innovative item types and accurate control over the test stimuli) and economically by reducing the costs of test administration (Csapó, Molnár \& Nagy, 2014). In addition, several factors motivate the use of technology in educational context like improving the assessment of already established assessment domains(Csapó, Ainley, Bennett, Latour \& Law, 2012) and measuring constructs which is difficult to do without the mean of technology (see Greiff, Wüstenberg, \& Funke, 2012; Greiff, Wüstenberg, Holt, Goldhammer, \& Funke, 2013). Some further benefits are the possibility of (1) adaptive testing, that is, the tests can be personalized and tailored to the need of the individual students; (2) instant and more personalized feedback, which allows learners to see how they did on the test; (3) using innovative item types with multimedia elements, automatic changing elements, interactive tasks etc.; (4) increased level of test security; (5) administering more objective, reliable and valid assessments with reduced costs of test administration; and (6) rethink the aim of educational assessment (from efficient testing to personalised learning) (see Csapó \& Molnár, 2017).On international level the most prominent large-scale assessments (e.g. OECD PISA) had a huge impact on the development of CBA (However, Palestine does not take part in the PISA assessment). To sum up, traditional assessment methods can be replaced by more efficient technology-based assessment (Csapó, Molnár \& Nagy, 2014) even in educational context. 


\subsection{Inductive reasoning}

Inductive reasoning is one of the most important thinking skills (Molnár et al., 2013), and it is one of the most frequently studied construct of cognition. It makes possible to use "existing knowledge to make predictions about novel cases" (Hayes \& Heit, 2017: 1), by operations and processes of moving from the specific to the general (Sandberg \& McCullough, 2010), and by doing generalization of single observations and experiences in order to reach general conclusions or derive rules. The history of development IR tests go back for more than two decades with the aim of developing (Csapó, 2007) and measuring the developmental level of IR (Csapó \& Nikolov, 2009).

The importance of Inductive reasoning can be seen in the point of its strong relatedness to almost all higher order thinking skills (Csapó, 1997; Molnár et al., 2013; Schubert et al., 2012).It plays an important role in learning, especially, in the processes of knowledge acquisition and application (Hamers, De Koning \& Sijtsma, 2000) which has high impact on the development of students' performance (Goldman \& Pellegrino, 1982). Its developmental level is correlated with the level of analogical reasoning (Goswami, 1991), problem solving (Wu \& Molnár, 2018; Klauer, 1996; Tomic, 1995) and intelligence in general (Klauer \& Phye, 2008). In addition, IR plays an important role in developing expertise (Cheng \& Holyoak, 1985) and it helps to understand the subject matter in the classroom deeply (Molnár, 2011). In connection with the previous point, Csapó \& Nikolov (2009) pointed out that IR development helps students to be successful in a wide range of domains in the learning process, however, the fostering of it is generally not an integral part of the school curricula (de Koning, 2000).

\subsection{ICT in the Palestinian education system}

In 2002, the Palestinian education system started to implement Information and Communication Technologies (ICT) at schools. Later no, more attention has been given to develop and modernise this field. Several initiatives announced like developing the infrastructure, creating capacity building, digitize the curriculum, creating digital content that can be accessed on modern education devices, building capacity of teachers who are able to use technology in teaching, etc. (Shraim, 2018). According to PMEHE (Note 1) (2018) statistics, more than $78 \%$ of the schools have computer laboratories and $72 \%$ of these are connected to the internet. The process of the development is moving forward to cover all of the schools with computer labs and other digital devices.

\section{Aims and research questions}

This study investigates the possibility of applying computer-based assessment in Palestinian educational context, in the Palestinian schools. A Hungarian online test adapted to Arabic format in language and direction has been applied to test and detect the applicability of computer-based assessment in the Palestinian schools. Beyond applicability, the present paper addresses the relationship that inductive reasoning has with academic achievement.

We thus intend to answer the following four research questions: (RQ1) is computer-based assessment applicable among fourth and fifth grades at schools in Palestine? (RQ2) is there any tangible development of inductive reasoning between fourth and fifth graders? (RQ3) are there 


\section{MlMacrothink}

any gender differences detectable? (RQ4) are students' school achievement and their level of inductive reasoning skill and the educational level of their mother related, especially, does the level of students' inductive reasoning skill predict academic achievement?

\section{Methods}

\subsection{Participants}

The sample of the study was drown from 4th and 5th graders (aged $\pm 9-10$ ) in Palestinian primary schools. There were 248 participates in this study, 138 male and 110 female students. The entire classes of students were selected for this study since classes in the Palestinian schools are updated each year by remixing students from different sections ( i.e. fifth grade has three sections A, B \& C) to have the ideal cure regarding students' ability (advanced, intermediate and low) in each class. Based on their school achievement, students were divided into three groups: low, intermediate and high performers.

\subsection{Instruments}

A computer-based inductive reasoning test was used in this study. Different formats with different levels of difficulty of inductive reasoning items were administered via the online assessment eDia (Molnár \& Csapó, 2019). The test consists of 60 items in total divided into four different subtests: figural series (18 items), figural analogies (18 items), number series (16 items) and number analogies ( 8 items). Students completed tasks by moving objects (figures or numbers) on the screen by drag-and-drop function. Sample items of the inductive reasoning test are presented in Figure 1. The students were asked to identify and point out relationships, similarities or differences, and dissimilarities in a series or analogies, between groups of figures or numbers.

In both the figural and number series tasks students had to figure out the rule lag behind the taskthen drag the right answer below the line on screen to complete the sequence. In case of figural and number analogies, students also needed to find out the missing shape or number that fits into the empty box regarding a rule. The rule could have been figured out in each of the tasks unequivocally.
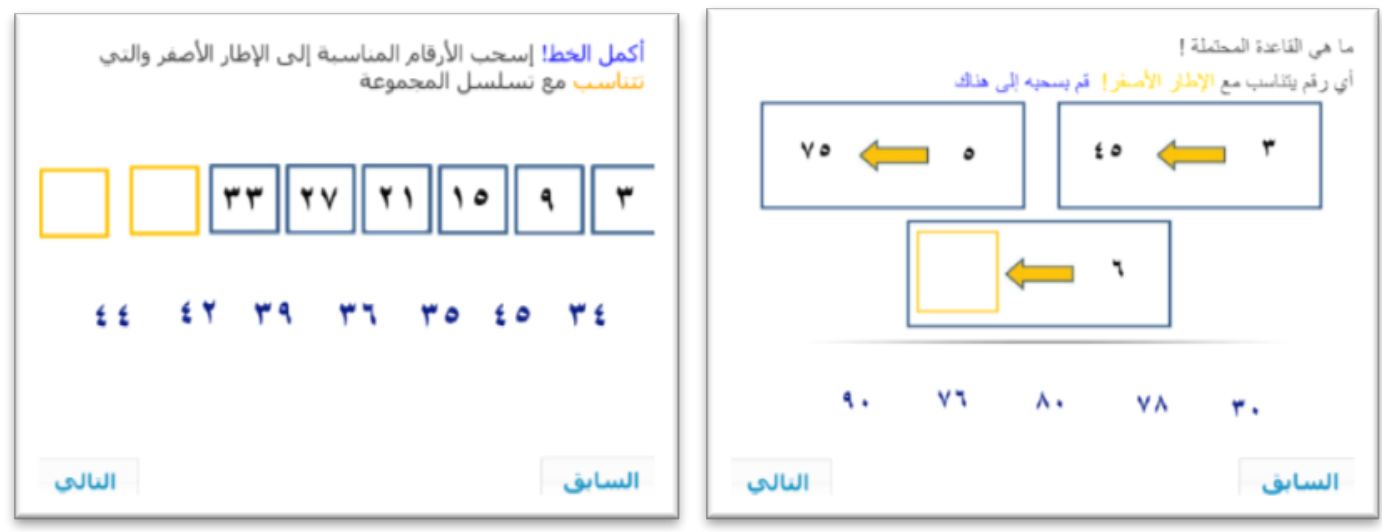

Figure 1. Samples of numerical series and numerical analogy items 


\section{MlMacrothink}

The items of the test have been selected and adapted from a scaled item bank for inductive reasoning developed in Hungary. Later, all items have been adapted to be suitable for the Arabic style as the following: the direction of the items have been changed according to the Arabic way by mirroring them (see Figure 2), the instructions have been translated into the simplified Arabic language and attached to the system in a text form. The tasks have been scored automatically. Students' responses were scored as "1" if it was fully correct; otherwise, the response was scored as incorrect ("0"). The students received instant feedback at the end of the test.
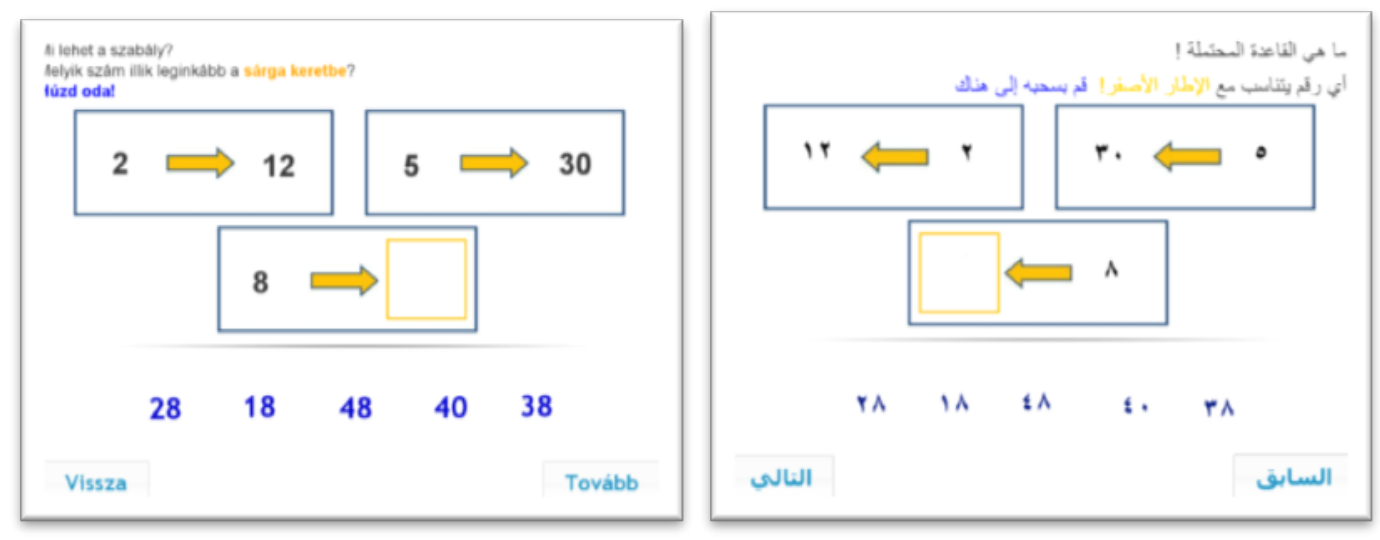

Figure 2. The same item from the original Hungarian and the Arabic version of the inductive reasoning test

\subsection{Procedures}

The test was administered in equipped computer labs using the online eDia platform. At the beginning, participants get instructions about the usage of the user interface that includes also a warm-up task with the aim of improving the feasibility of the assessment and validity of the results. The instructions were given in written format. A yellow progress bar at the top of the screen indicated students' current spot in the test, that is, how far they were in the test.

Students' inductive reasoning performance was automatically scored, thus, they received immediate performance feedback at the end of the testing session. The test took approximately one hour to complete. Testing sessions were supervised by classroom teachers who had been fully trained in test administration. Both the functions of classical test theory (Cronbach-alpha, bivariate correlation, t-test, mean, standard deviation) and item response theory (IRT) were employed by the analyses.

Rasch analyses were used to test the appropriateness of the tasks regarding its difficulty level. The four-dimensional item/person map shows how the distributions of students and items in each of the subtests relate to one another by locating both items and students on the same scale. The ability measure of students is on the left side of the figures, while the difficulty distributions of the items in each of the dimensions are on the right. More difficult items are positioned higher on the scale than less difficult ones. Students with a higher ability level are positioned higher on the same scale then students with a lower ability level. Students and items 
are located at the same level if the ability level of the student is equal to the difficulty level of the item, that is, if the student has a $50 \%$ chance of correctly answering the item.

\section{Results}

Internal consistencies (Cronbach-alpha) of the inductive reasoning test was good $(\alpha=.807)$, that is, the results of the study are reliable and generalizable. Students were able to finish the test on time and answer the questions using drag-and-drop operations with the mouse. Thus, computer-based testing is applicable at the age of 9-10 in the Palestinian school system, when drag-and-drop items are used (RQ1).

Based on participants' mean and row score distribution, the test proved to be difficult for the students at this age $(\mathrm{Min}=6.67, \mathrm{Max}=53.33, \mathrm{M}=25.29, \mathrm{SD}=10.94)$. The subtest-level analyses indicated that the identification of similarities or differences, and dissimilarities in a series or analogies were significantly easier if it was going about figures and not numbers. The same operations proved to be harder on an average if the content changed to numbers, thus, items having mathematics context and require counting proved to be much harder, especially, if they belonged to the number series subtest (see Table 1).

Table 1. Sub-test level descriptive statistics of the IR test

\begin{tabular}{lccccc}
\hline \multicolumn{1}{c}{ Sub-tests } & Items & Min & Max & Mean & SD \\
\hline Figural Analogy & 18 & .00 & 83.33 & 32.63 & 17.72 \\
Figural Series & 18 & .00 & 83.33 & 41.30 & 19.01 \\
Number Analogy & 8 & .00 & 87.50 & 16.63 & 15.15 \\
Number Series & 16 & .00 & 18.75 & 3.35 & 4.99 \\
\hline
\end{tabular}

According to the four-dimensional item/person map (Figure 3) there were big differences in students' achievement in the four dimensions of IR. The achievement-based distribution curves were very similar in case of the figural items, which difficulty level fit to the ability level of the students. But they strongly differed by items based on number series, which were too hard for the target population, for the 4 th and $5^{\text {th }}$ graders. However, the distribution of the items according to its difficulty was good in each of the dimensions, that is, there were easy, medium and hard items in each of the dimensions. 
Num. An. Num. Ser. Fig An. Fig Ser. titem

\begin{tabular}{|c|c|c|c|c|}
\hline \multirow[t]{5}{*}{2} & । & । & । & । \\
\hline & । & । & । & $x \mid$ \\
\hline & I & । & । & $\mathrm{x} \mid 32$ \\
\hline & I & । & 1 & 157 \\
\hline & । & । & । & XI10 $12 \quad 15 \quad 17 \quad 23 \quad 49 \quad 58$ \\
\hline \multirow[t]{5}{*}{1} & । & । & I & $x X \mid 39 \quad 40 \quad 55$ \\
\hline & I & । & $x \mid$ & $\mathrm{XXX} \mid 5 \quad 6 \quad 41 \quad 59$ \\
\hline & । & । & $\mathrm{XX} \mid$ & XXXX|9 $20 \quad 36 \quad 46 \quad 47$ \\
\hline & । & । & XXXI & $\mathrm{xxxxx} \mid 38$ \\
\hline & I & । & XXXI & XXXXXX|4 52 \\
\hline \multirow[t]{5}{*}{0} & । & । & XXXXX| & XXXXXXX|2 $8333 \quad 34 \quad 37$ \\
\hline & । & । & XXXXXI & $\begin{array}{lllllll}\text { XXXXXXX|3 } & 11 & 16 & 27 & 31 & 45 & 48\end{array}$ \\
\hline & $\mathrm{XX} \mid$ & । & XXXXXXI & XXXXXX|13 $14 \quad 18 \quad 26 \quad 28 \quad 53 \quad 56$ \\
\hline & $\mathrm{XX} \mid$ & | & XXXXXXXX| & XXXXXXXX|35 $44 \quad 60$ \\
\hline & $\mathrm{XXX} \mid$ & । & XXXXXXXX| & XXXXXXX|24 50 \\
\hline \multirow{5}{*}{-1} & XXXXI & । & XXXXXXXXI & $\begin{array}{llll}X X X X X \mid 1 & 7 & 29 & 42\end{array}$ \\
\hline & XXXXXX| & & XXXXXXXXX| & XXXXXX|30 \\
\hline & XXXXXXX| & । & XXXXXX| & XXXXXX|25 $43 \quad 5154$ \\
\hline & XXXXXXXXXX| & । & XXXXXXXI & $\mathrm{XXX} \mid$ \\
\hline & XXXXXXXXXX| & । & XXXXXXI & $\mathrm{XXX} \mid$ \\
\hline \multirow[t]{5}{*}{-2} & XXXXXXXXXX| & । & XXXXI & $\mathrm{XI}$ \\
\hline & XXXXXXXXXI & । & XXI & $\mathrm{XI}$ \\
\hline & XXXXXXI & । & $\mathrm{XX1}$ & $x \mid 22$ \\
\hline & XXXXXXXI & । & XI & $\mathrm{XI}$ \\
\hline & XXXXXI & $\mathrm{XX} \mid$ & 1 & 1 \\
\hline \multirow[t]{5}{*}{-3} & $\mathrm{XXX1}$ & $\mathrm{XX} \mid$ & । & 1 \\
\hline & $\mathrm{XXI}$ & XXXI & । & 1 \\
\hline & I & $\mathrm{XX} \mid$ & 1 & 121 \\
\hline & I & XXXI & 1 & 1 \\
\hline & 1 & XXXX| & 1 & 1 \\
\hline \multirow[t]{5}{*}{-4} & 1 & XXXXXI & 1 & । \\
\hline & 1 & XXXXXI & 1 & 1 \\
\hline & I & XXXXXXX| & । & 1 \\
\hline & I & XXXXXXX| & 1 & I \\
\hline & 1 & XXXXXXXI & 1 & 1 \\
\hline \multirow[t]{5}{*}{-5} & 1 & XXXXXXXI & 1 & 1 \\
\hline & I & XXXXX| & 1 & I \\
\hline & I & $\mathrm{XXX} \mid$ & 1 & 1 \\
\hline & I & XXXXX| & 1 & । \\
\hline & 1 & XXXXXI & 1 & 1 \\
\hline \multirow[t]{2}{*}{-6} & I & XXXXI & 1 & I \\
\hline & I & $\mathrm{XX} \mid$ & 1 & | \\
\hline
\end{tabular}




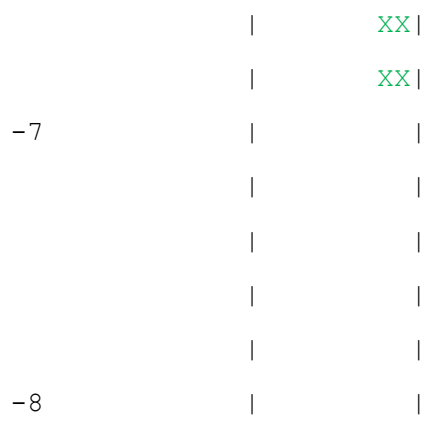

Figure 3. The four-dimensional item/person map (each X represents 3 students; blue: num. analogies, green: number series, orange: figural analogies, red: figural series)

Students in Grade 5 achieved significantly higher than its mates in Grade 4 (M_grade4=23.88, $\mathrm{SD}=10.26 ; \mathrm{M} \_$grade $\left.5=26.68, \mathrm{SD}=11.44 ; \mathrm{t}=-2.02, \mathrm{p}<.05\right)$. This indicates that the age of $9-10$ could be a sensitive period for enhancing students' inductive reasoning skills as even without explicit training significant development occurred (RQ2).

No significant gender level differences were detected on both sample (M_girls=26.75, $\mathrm{SD}=9.81 ; \mathrm{M}$ boys=24.13, $\mathrm{SD}=11.66 ; \mathrm{t}=-1.92, \mathrm{p}>.05$ ) and grade level (see Table 2). Male and female students achieved at the same level in the same grade. However, Figure 4 indicates some differences between male and female students' behaviour in the IR test (RQ3)

Table 2. Grade and gender-level differences in students' IR skills

\begin{tabular}{clllll}
\hline Grade & Gender & Mean & SD & t & p \\
\hline \multirow{2}{*}{4} & Female & 24.78 & 9.20 & & \\
\cline { 2 - 4 } & Male & 23.18 & 11.03 & & \\
\cline { 2 - 4 } 5 & Female & 28.66 & 10.08 & & $\mathrm{p}>.05$ \\
\cline { 2 - 4 } & Male & 25.07 & 12.27 & & \\
\hline
\end{tabular}

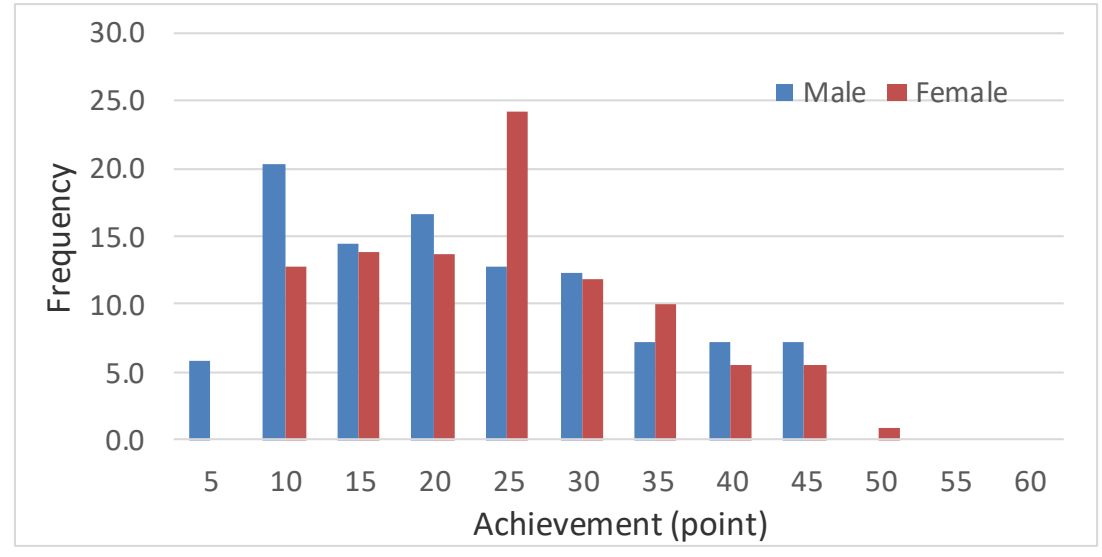

Figure 4. Gender level distribution curve of IR 


\section{Mll Macrothink}

Journal of Studies in Education

ISSN 2162-6952

2019, Vol. 9, No. 3

There are several factors that could influence students' level of inductive reasoning skills. In this regard, we focused mainly on the educational and occupational level of the mother since she plays an immense role in the education of the Palestinian children. The results confirmed our hypotheses and proved that the mother's educational background has a strong influential factor on students' achievement in the IR test $(\mathrm{r}=.691, \mathrm{p}<.01)$; the mother's occupational background also influenced strongly the achievement of the students $(r=.470, p<.01)$. Students with more educated mothers have higher level of inductive reasoning skills than students with less educated mothers. Students' school achievement had also a strong relationship with their test-level achievement $(\mathrm{r}=.897, \mathrm{p}<.01)$, that is, students with higher school achievement proved to be more developed in inductive reasoning skills, thus the development and evaluation of students IR skills are hidden embedded in the Palestine school curricula and evaluation process (RQ4).

Students' level of inductive reasoning had a strong effect on their school achievement (M_school_advanced $=40.08$, M_school_average $=25.48 ;$ M_school_low $=14.50, \mathrm{~F}=528.16$, $\mathrm{p}<.001 ; \mathrm{r}=.89, \mathrm{p}<.001)$. Students with higher level reasoning skills belonged to the top performers based on their school marks, while students with lower level thinking skills belonged to the low performers even at school level. This result also confirms that the development and evaluation of thinking skills, especially inductive reasoning skills are present implicitly in the Palestinian school curriculum (RQ4).

\section{Conclusion}

This study presented issues related to the the feasibility and the applicability of computer-based assessment when it comes to early age pupils among Palestinian students. Many challenges and questions have been raised regarding administering computer-based tests at early age students. We also investigated the visibility of inductive reasoning skills in the Palestinian curriculum by analysing the results of students' achievement and comparing gender and grade-level differences and detecting the influential factor of mothers' education on students reasoning skills and the relationship between students' inductive reasoning skill and academic achievement.

The results of our study supported previous studies (Molnár \& Pásztor, 2015) about the possibility of using computer-based assessment at the early age pupils. It confirmed that computer-based testing can be introduced in the Palestinian school system even at early ages and students are able to do computerised tests in an efficient way. It can also be said that the Palestinian school curriculum integrates the development of inductive reasoning in it where the visibility of it can be seen on students' performance as the more the student grows up in age at school; the more the inductive reasoning skills develop. The evaluation of it is embedded in the school marks.

\section{Notes}

Note 1. PMEHE stands for the Palestinian ministry of education and higher education 


\section{References}

Bottino, R., Ferlino, L., Ott, M. \&Tavela, M. (2007). Developing strategic and reasoning abilities with computer games at primary school level. Computer \& Education, 49(1), 1272-1289. https://doi.org/10.1016/j.compedu.2006.02.003

Cheng, P. \& Holyoak, K. (1985). Pragmatic versus syntactic approaches to training deductive reasoning. Cognitive Psychology, 17(1), 391-416. https://doi.org/10.1016/0010-0285(85)90014-3

Clariana, R. \& Wallance, P. (2002). Paper-based versus computer-based assessment: key factors associated with test mode effect. British Journal of Educational Technology, 33(5), 593-602. https://doi.org/10.1111/1467-8535.00294

Csapó, B. (1997). The development of inductive reasoning: Cross-sectional assessments in educational context. International Journal of Behavioral Development, 20, 609-626. Doi:10.1080/016502597385081

Csapó, B., (2007). "Hosszmetszetifelmérésekiskolaikontextusbanazelso" átfogó agyariskolailongitudináliskutatási program elméletiésmód-szertanikeretei [Longitudinal assessments in school context - the oreticaland methodological frameworks of the first large-scale school-related longitudinal program in Hungary],". Magyar Pedagógia, 107, pp. $321-355$.

Csapó, B., Ainley, J., Bennett, R., Latour, T. \& Law, N. (2012). Technological issues of computer-based assessment of $21^{\text {st }}$ century skills. In B. McGaw, P. Griffin, \& E. Care (Eds.), Assessment and teaching of 21 century skills (143-230). New York, NY: Springer. https://doi.org/10.1007/978-94-007-2324-5_4

Csapó, B., Lörincz, A. \& Molnár, G. (2012). Innovative assessment technologies in educational games designed for young students. Assessment in Game-Based Learning, 235-254. https://doi.org/10.1007/978-1-4614-3546-4_13

Csapó, B. \& Molnár, G. (2017). Assessment-based, personalised learning in primary education. In Spender, J. C., Gavrilova, T., \& Schiuma, G. (Eds.), Knowledge management in the 21st century: Resilience, creativity and co-creation (pp. 443-449). Proceedings IFKAD2017. St Petersburg University, St. Petersburg.

Csapó, B., Molnár, G., \& Nagy, J. (2014). Computer based assessment of school readiness and early reasoning. Journal of Educational Psychology, 106(3), 639-650. https://doi.org/10.1037/a0035756

Csapó, B, Molnár, G., \& R. Tóth, K. (2009). Comparing paper-and-pencil and online assessment of reasoning skills: A pilot study for introducing TAO in large-scale assessment in Hungary. In F. Scheuermann, \& J. Björnsson (Eds.), The Transition to Computer-Based Assessment: New Approaches to Skills Assessment and Implications for Large-scale Testing (pp. 113-118). Luxemburg: Office for Official Publications of the European Communities. 
Csapó, B., \& Nikolov, M. (2009). The cognitive contribution to the development of proficiency in a foreign language. Learning and Individual Differences, 19, 209-218.

de Konig, E. (2000). Inductive Reasoning in Primary Education: Measurement, Teaching, Transfer. Zeist, Kerckebosch.

Goldman, S., \& Pellegrino, J. (1982). Development and individual differences in verbal analogical reasoning. Child development, 53(1), 550-559. https://doi.org/10.2307/1128998

Goswami, U. (1991). Analogical reasoning: what develops? A review of research and theory. Child Development, 62(1), 1-22. https://doi.org/10.2307/1130701

Greiff, S., Wüstenberg, S., \& Funke, J. (2012). Dynamic problem solving: A new assessment perspective. Applied Psychological Measurement, 36, 189-213.

Greiff, S., Wüstenberg, S., Holt, D. V., Goldhammer, F., \& Funke, J.(2013). Computer-based assessment of complex problem solving: Concept, implementation, and application. Educational Technology Research and Development, 61, 407-421.

Hamers, J., De Koning, E., \& Sijtsma, K. (2000). Inductive reasoning in the third grade: intervention promises and constraints. Contemporary Educational Psychology, 23(1), 132-148.

Hayes, BK. \& Heit, E. (2017). Inductive reasoning 2.0, Wiley Interdisciplinary Reviews: Cognitive Science, 9(3), 1-13. http://dx.doi.org/10.1002/wcs.1459

Klauer, K. (1996). Begünstigt induktives Denken das Lösen komplexer Probleme? ExperimentellenStudienzuLeutnerssahel-Problem [Has inductive Thinking a positive effect on complex problem solving?]. Zeitschrift für Experimentelle Psychologie, 43(1), 361-366 (Dutch version).

Klauer, K., \& Phye, G. (2008). Inductive reasoning: a training approach. Review of Educational Research, 78(1), 85-123.https://doi.org/10.3102/0034654307313402

Molnár, G. (2011). Playful fostering of 6- to 8-year-old students' inductive reasoning. Thinking Skills and Creativity, 6(2), 91-99. https://doi.org/10.1016/j.tsc.2011.05.002

Molnár, G., \& Csapó, B. (2019). How to Make Learning Visible Through Technology: The eDia-Online Diagnostic Assessment System. In Lane, H., Zvacek, S., \& Uhomoibhi, J. (Eds.), CSEDU 2019. Proceedings of the 11th International Conference on Computer Supported Education, 2. Heraklion, Crete: Scitepress. 122-131.

Molnár, G., Greiff, S., \& Csapó, B. (2013). Inductive reasoning, domain specific and complex problem solving: Relations and development. Thinking Skills and Creativity, 9(1), 35-45. https://doi.org/10.1016/j.tsc.2013.03.002

Molnár, G., \& Pásztor, A. (2015). Feasibility of computer-based assessment at the initial stage of formal schooling: the developmental level of keyboarding and mouse skills in Year One. In Conference on Educational Assessment, Hungary, April 23-25, 2015, pp. 118. 
PMEHE. (2018). Educational Statistics 2016/2017. Palestine Ministry of Education and Higher Education, Ramallah. Retrieved on May 2018, from http://www.mohe.pna.ps/services/statistics

Sandberg, E., \& McCullough, M. (2010). The development of reasoning skills. In Sandberg, E. \& Spritz, B. (Eds.). A clinician's guide to normal cognitive development in childhood (179-189). New York: Routledge. https://doi.org/10.4324/9780203843697

Schubert, T., Astle, D., \& Van Der Molen, M. (2012). Computerized training of non-verbal reasoning and working memory in children with intellectual disability. Training-induced cognitive and neural plasticity.

Shraim, K. (2018) Palestine (West Bank and Gaza Strip). In: Weber A., Hamlaoui S. (eds) E-Learning in the Middle East and North Africa (MENA) Region. Springer, Cham, pp 309-332. https://doi.org/10.1007/978-3-319-68999-9_14

Thurlow, M.; Lazarus, S. S., Albus, D., \& Hodgson, J. (2010). Computer-based testing: Practices and considerations (Synthesis Report 78). Minneapolis, MN: University of Minnesota, National Center on Educational Outcomes.

Tomic, W. (1995). Training in inductive reasoning and problem solving. Contemporary Educational Psychology. 20(1), 483-490. The Open University, Heerlen, The Netherlands. https://doi.org/10.1006/ceps.1995.1036

Wu, H., \& Molnár G. (2018): Computer-based Assessment of Chinese Students' Component Skills of Problem Solving: A Pilot Study. International Journal of Information and Education Technology, 8(5), 381-356. https://doi.org/10.18178/ijiet.2018.8.5.1067 